\title{
Freedom of Expression and Communicative Equality
}

\author{
The Case for Regulation
}

\section{Renato Francisquini}

Renato Francisquini, 31, is currently a PhD candidate in Political Science at the University of São Paulo, Brazil. He is supported by the Conselho Nacional de Desenvolvimento Cientifico e Tecnologico (CNPq). His main interests are in Political Theory and Contemporary Theories of Justice, especially the discussion around the principles of deliberative democracy and freedom of expression. Renato is graduated in Communications by the Pontificial Catholic University and has a MA by the Federal University of Minas Gerais. This paper corresponds to the final part of his dissertation.

\begin{abstract}
This paper addresses the normative issue of free speech within the landscape of democratic societies where the mediated form of communication appears as a central feature. Contemporary discussions about free speech tend assimilate press freedom to a notion of freedom of expression as a negative liberty, so repudiating every single regulation to the mass media. In opposition to that line of thought, I argue that media freedom cannot be justified by analogy with negative liberty. The most convincing justification for the principle of freedom of expression relies on the idea of the fair value of communicative liberties, or the idea that society must assure fair opportunities for the exercise of communication. Following this account, I affirm that the institutions responsible for mediating the expressive acts should be structured in a way that contributes, at once, to individual self-determination and collective self-government.
\end{abstract}

Keywords: Deliberative democracy; Fair Value of Communicative Liberties; Freedom of Expression; Mass Media; Self-determination. 
To try to deny the citizen this freedom [of the pen], means withholding from the ruler all the knowledge of those matters which, if he knew about them, he would bimself rectify, so that he is thereby put in a selfstultifying position

Immanuel Kant - "On The Common Saying - "This may be true in Theory, but it Does Not Apply in Practice'”. In: Kant Political Writings).

\section{Introduction}

In an unprecedented decision, the Brazilian Court has convicted a Bandeirantes TV and its journalist José Luiz Datena for hate speech against atheists. They were convicted over a show aired on July 2010 in which Datena claimed that a supposed criminal could not be but an atheist. According to Datena, in a Dostoiesvkian argument, the alleged criminal's problem was the absence of god in his heart: "Atheists have no limits, that's why we see crimes like these. Atheists kill and commit other atrocities. They think they are their own God". After a protest from the Brazilian Atheist Association (ATEA), the Brazilian Court sentenced Bandeirantes to air a two hour show discussing freedom of consciousness and religious diversity.

The São Paulo Press Association reacted in a note opposing the conviction in which it states that "one cannot think of democracy in Brazil without fighting for the rights enshrined in the United Nations' Charter of Human Rights, which protects the human right to freedom of expression and therefore the right of communication (...). When a journalist or a TV station is prevented from the right to free speech, we disrespect democracy and the rule of law. This is not a discussion about freedom of consciousness or religious diversity; more important is the question of freedom of expression and the essential and legitimate right of communication. (...). We couldn't go without a retaliation note because the constitutional defense of one of the most important principles of natural law, that is the right to freedom of expression, is comparable to a defense of life and of the natural freedom of buman beings" $^{35}$.

\section{I.}

In contemporary societies the mass media play a central role in societies' symbolic reproduction; mediated discourses, be them informative or entertainment, form opinions, build identities and regulate political agency. Our comprehension of politics and society fundamentally depends on mass media's filters, which define the dynamics of inclusion-

35 Emphasis added. 
exclusion of legitimate voices. The media frames the content and the form of what circulates in the public sphere (Rummens, 2012).

From a certain point of view, the development of IT technologies and the spread of democratic practices have made it easier than ever to establish communication both widely and effectively. Yet some theoretically accepted concepts and legally enforced norms tend to restrict rather than to support democratic communication. I refer to views, such as the one espoused by the São Paulo Press Association, which assigns media and other corporations the same rights assigned to individuals.

In opposition to that line of thought, I will sustain that the free circulation of ideas is more adequately guaranteed when society promotes fairness with regard to the opportunities to exercise communicative liberties ${ }^{36}$. This perspective, which I shall defend, puts in the forefront of the debate a discussion regarding the regulation of free speech, from the discouraging of hate speech to legislations dealing with the propriety of the mass media.

In what follows I will present three different alternatives to the idea that freedom of expression is only guaranteed when the collectivity is denied any interference on individual expressive rights. First, I bring the "Millian" argument for the protection of free speech, which is based on the idea that freedom of expression is justified by the requirements of individual autonomy. Secondly, I present the "collectivist approach", that argues that only those expressions that contribute to the democratic deliberation of self-governing citizens should be protected. Third, I address the "participatory theory", which justifies constitutional protection for certain speech acts on the expressive interest of the speakers in participating in self-determination processes. My argument is that, all in all, these perspectives fail to provide an adequate justification for regulating free speech. I will defend that society must guarantee the fair value of communicative liberties. Everyone shall have the same rights and the adequate conditions to express themselves and to be heard in the process of defining society's destiny. Following this path, I shall reason that

Fair equality of opportunity here means liberal equality. To accomplish its aims, certain requirements must be imposed on the basic structure beyond those of the system of natural liberty. A free market system must be set within a framework of political and legal institutions that adjust the long-run trend of economic forces so as to prevent excessive concentrations of property and wealth, especially those likely to lead to political domination (Rawls, 2003: 44).

36 According to Iris Young,"Democracy is a process of communication among citizens and public officials, where they make proposals and criticize one another, and aim to persuade one another of the best solution to collective problems" (2010, pp. 52). 
II.

Freedom of expression is commonly associated with the search for truth and with the proper functioning of democracy. To the guarantee of freedom of expression is often assigned an epistemic value: better decisions are related to the free circulation of ideas and/or to the diversity of viewpoints available in the public space.

According to Scanlon, a strong doctrine of freedom of expression holds that some speech acts must be immune from interference, despite the harms they could cause and that would be sufficient for the prohibition of other kinds of acts (Scanlon, 2003b: 6). If this is the case, it is necessary to justify the privilege certain speech acts are entitled to. Although part of the discussion follows in a consequentialist path, in this paper I will focus on the discussion that allows us to assess the rationale that underlies the practices regarding the regulation of free speech.

Following John Stuart Mill's On Liberty, Scanlon argues that the justifications for regulating freedom of expression should not be sustained on the argument that, if unrestricted, it would lead people to form false beliefs or to consider performing potentially harmful acts. Based on the Kantian ${ }^{37}$ idea that a legitimate government is the one whose authority is acknowledged by the citizens, considered free, equal, autonomous and rational, Scanlon presents what he calls the Millian Principle:

There are certain harms which, although they would not occur but for certain acts of expression, nonetheless cannot be taken as part of a justification for legal restrictions on these acts. These harms are: (a) harms to certain individuals which consist in their coming to have false beliefs as a result of those acts of expression; (b) harmful consequences of acts performed as a result of those acts of expression, where the connection between the acts of expression and the subsequent harmful acts consists merely in the fact that the act of expression led the agents to believe (or increased their tendency to believe) these acts to be worth performing (Scanlon, 2003b: 14).

This is an "exceptionless" restriction on governmental authority, a limit on the reasons one can use to justify government interference on individuals' freedom of expression $^{38}$.

At first glance, it seems that Scanlon is providing an unlimited defense for all types of discourse, once he argues that freedom of expression is a good we intuitively rank as

37 Though, as he argues, the requirements for autonomy he subscribes are far weaker than the requirements Kant draws for this notion.

38 It should not, therefore, be considered an individual right. 
more important than others. However, the argument has a limited reach, though the limits should be defined by considerations external to the idea of freedom of expression.

Access to means of expression for whatever purposes one may have in mind is a good which can be fairly or unfairly distributed among the members of a society, and many cases which strike us as violations of freedom of expression are in fact instances of distributive injustice. This would be true of a case where, in an economically inegalitarian society, access to the principal means of expression was controlled by the government and auctioned off by it to the highest bidders, as is essentially the case with broadcasting licenses in the United States today (Scanlon, 2003b: 22).

By placing the case for fair communicative opportunities outside the domain of free speech and ranking the right to individual self-expression as more important than other considerations, Scanlon subjects the fair value of political liberties to (a certain conception of) individual autonomy. His argument is committed to the protection of the capacity one has to see herself as "sovereign in deciding what to believe and in weighing competing reasons for action" (2003b: 15) ${ }^{39}$.

Let's consider, however, a person who is socialized in an environment where public discourse tends to picture those of her class, race or sex as mere instruments for others' ends. In this same society, TV news and entertainment shows constantly present scenes of violence involving people with one or more of certain ascriptive characteristics, as if they were naturally leaning to behave in harmful ways. Would such a person be in a position to consider herself as an equal member of the society? Would she see herself and those who share the same characteristics as self-governing individuals and act accordingly?

It is impossible not to take into account the sour-grapes phenomenon among those who were socialized in a society where they are not entitled to equal opportunities. In other words, self-determination is affected not only by the person's own choices; it is also an outcome of the belief system that tells someone what the available alternatives are (Brison, 1998).

If we recognize that the "social basis of self-respect" (Rawls, 2003: 59) is a fundamental feature of human dignity and a requirement of social and political agency in conditions of equality, Scanlon's formulation opens space for inequalities that undermine the necessary conditions for exercising collective and individual self-determination.

39 Later, Scanlon himself recognized that "the Millian Principle,..., placed too tight a constraint on possible justifications for restricting expression” (2003a, p. 2). 


\section{III.}

A different account of freedom of expression rests on the idea that protecting free speech is a form of enhancing public deliberation. According to this perspective "what is essential is not that everyone shall speak, but that everything worth saying shall be said" (Meiklejohn, 1948: 26). Constitutional protection to free speech is a form of avoiding the mutilation of society's "thinking process" rather than a protection of individual rights to free expression. He proposes that the traditional model of town meetings found in some parts of the United States is a pattern from which one can assess the quality of public debate in society as a whole.

Thus, this version highlights the protection of the listener's ability to receive information and opinions from different sources in order to make wise decisions. According to this argument, a system that gives people opportunity to speak but does not offer the necessary tools to think, will be full of empty speech and reckless voting (Gastil, $2008)^{40}$.

Meiklejohn believes the fact that popular sovereignty requires a free and open discussion among citizens would run against the justification for government interference on political discussion. In line with Scanlon's argument, the collectivist view condemns the restrictions based on the point of view of the speeches, because they could silence certain voices, causing interference on public debate, and, consequently, reducing the legitimacy of democratic decisions. At the same time, however, this view opens space for rules applied to the procedure of public debate in order to guarantee the quality of political deliberation. Hence the state can work to restrict or to guarantee freedom of expression, even when it deals with distributive issues. For instance, in determined contexts, private actors who control the means by which ideas come into public sphere can restrict free speech. In such situations, the state must play an affirmative role in order to secure that citizens will receive all the important information needed to base their decisions. Government abstention may be responsible for the exclusion of some ideas from public deliberation (Fiss, 1996).

Nevertheless, the collectivist approach protects speech only insofar as an idea could be seen as contributing to the society's thinking process. The authors attached to this perspective distinguish private from public speech, assigning constitutional protection only to the latter. Following this line of thought, the government would be free to restrict, for example, certain forms of hate speech, based on the premise that the ideas they convey are

40 This is quite the same idea espoused by Dahl in the criterion of enlightened understanding. Cf Dahl (2006). 
not contributions to public deliberation and collective self-determination. At the same time, however, it would not be precluded from restricting some forms of artistic expression or religious content, based on the same argument. In not protecting such speeches, the collectivist approach does not acknowledge the mutual presupposition of political and “non-political” liberties (Cohen, 1998).

Although the theory refers the value of free speech to the effects it has on the audience, public and private discourses are a function of the speaker's intentions, not of the potential effects on the listeners. This perspective, thus, implicitly imposes, to the distinction between discourses that should and should not be protected, a comprehensive conception of what must be valued by society. It refuses constitutional protection to private speech based on the normative idea that the self-interest disqualifies expressions as relevant contributions to democratic deliberation. According to Redish and Mollen (2009), "a speaker who refuses to believe in the value of community and instead seeks solely to further his own personal interests through expression is to be constitutionally shunned" (2009: 1318-9). According to Post,

If the state excludes communicative contributions on the grounds of a specific sense of what is good or valuable, the states then stands in contradiction to the central project of collective self-determination. It displaces that project for the sake of heteronomously imposed norms. The internal logic of self-government thus implies that with regard to the censorship of speech the state must act as though the meaning of collective identity were perpetually indeterminate within the medium of public discourse, where 'the debate as to what is legitimate and what is illegitimate must necessarily remain 'without any guarantor and without any end' (1995: 1116).

Moreover, although this approach leaves the content of the government's decisions opened for the citizens' deliberation, it closes the framework of democratic discussion, isolating it from the public sphere. The town meetings are organized according to specific and shared goals. Being the agenda and purposes defined beforehand, the rules are formulated and established to facilitate their implementation. By isolating the decision about what should be said from the democratic procedure, the collectivist view needs to appeal to some form of management through which it would decide whether "everything worth saying" has been said. It requires an a priori agreement on the goal(s) that should drive public deliberation or a moderator whose legitimacy entitles her to conduct public discussion. 
IV.

According to Post (1995), public discourse presupposes that all beliefs, all goals and all conceptions about the role of the state are opened to public scrutiny, as well as the agenda of the discussion. According to him, what shall be said and what is a valid argument are also subject to disagreement and dispute. No particular comprehensive conception could be used to justify censorship. This would stand in contradiction with the exercise of self-determination through the public use of reason. Appeals to ideas of equality or diversity refer to particular notions of the common good, not necessarily shared by all. Following an argument made by Foucault, Post reasons that control structures end up coming to life and threatening even the autonomy of those who created it: "If we create structures of heteronomy, we shall all, sooner or later, be condemned to inhabit them. We shall become the subjects of a power not our own" (Post, 1995: 1129).

The legitimacy of a political order, argues Post (1995), is due to the citizens' belief in government's responsiveness to their interests, and to the view of the state as an outcome of their self-determination. So the key question is to realize how the citizens would feel included in the process of collective self-government. He reasons that the public discourse enterprise can create the consensus necessary for the citizens to view society as a self-governing body. In other words: public communication is able to produce consensus and, as a result, democratic legitimacy. Hence, society must protect the opportunities citizens have to engage in public discourse ${ }^{41}$. Because there cannot be a fusion between individual and collective will (á la Rousseau), citizens may only "embrace the government as rightfully 'their own' because of their engagement in these communicative processes" (Post, 1995: 1115). Free speech, in this sense, is internally related with the safeguard of public debate; nevertheless, this requirement is to be understood as excluding regulations that affect speakers' expressive interests.

Self-government thus rests, ultimately, on the distinction between autonomy and heteronomy. Any form of interference in the public discourse might be understood as excluding some citizens from the medium of collective self-determination. The communicative processes that give rise to collective will should allow citizens and the society to continuously reconstruct their own identities and their orientation on the moral space. For this reason, public discourse is not organized to accomplish any specific function or purpose; instead, it serves as a medium through which diverse conceptions of

41 Tied to this requirement is the obligation to subordinate the democratic will of the political system to the public opinion generated in the public sphere. 
the good life can freely collide and reconcile. What follows from this assumption is that the communicative processes must not be managed in any sense, because this would contradict the very nature of its democratic purposes.

The democratic deliberation, in this sense, will be continuously available for the individual and collective inputs of the citizens. Particular conceptions of equality and equal protection can only acquire legitimacy because public discourse is pervasively indeterminate, and it gives space for the support, the critic, the rejection, and the replacement of such comprehensive notions of the common good. Self-determining frameworks must situate individuals within "webs of hermeneutic interactions" (Post, 1995: 1131), understanding them as autonomous and capable of self-government ${ }^{42}$. Autonomy, therefore, works as a "moral ascription" of the commitment with selfgovernance.

As we can see, this perspective place prominent value to citizen's participation, understood as private inputs into the communicative process. There is no concern whatsoever with the listeners and bystanders, and with the resources they have available for making democratic decisions. Autonomy, in what Post (1995) denominates the "traditional First Amendment jurisprudence", implies a sphere free from interference of any kind.

The participatory theory has the advantage of rejecting a managerial control over free speech and public discourse. Moreover, it protects some forms of expression that would not be guaranteed protection by the collectivist approach. Post does not argue for no regulation; rather, he rejects rules based on comprehensive conceptions of national identity that are applied by the collectivity over private actors.

I would like to argue, nevertheless, that by rejecting public interference on the communicative structure that sustains self-expression, this theory seems to understand that a regulation by private actors would be more fair and would give rise self-determination (Silva, 2009). We must inquire if is it really the case of living it all for the form of communication that is promoted by the market, with no concern with the requirement of equality in the chances we all have to participate in self-determination.

Communication should be valued, among other reasons, because the audience participates as much as the speakers on the formation of the public opinion to which the government might subordinate its decisions. Self-government is a collective enterprise and cannot be realized without assuring equal opportunities for making inputs to the

42 A notion of autonomy as the one subscribed by the collectivist approach attaches this ideal to requirements of education and the amelioration of social conditions. It implies that it has to be achieved instead of being ascribed. 
communicative processes through which decisions gain legitimacy. If a speaker has a right to self-expression but lacks the capacity to achieve her intended audience, would she feel as a participant of collective self-government?

In order to protect certain notions of autonomy and self-determination, this approach refers to a principle of tolerance that, if blindly followed, denies some individuals and groups a rightful place in society. As Cohen argues, when the state fails to impede private actors to restrict others' equal expressive liberties, it is not acting to protect freedom of expression and, therefore, the right to self-determination (1993, pp. 216-9).

The access to the means of publishing and/or broadcasting is equivalent to the right to express oneself. The "marketplace of ideas" is a misleading metaphor when it suggests that our media system is nothing but a reflex of society (Gutman \& Thompson, 1996: 125). Under the current conditions in most of our established occidental democracies the communicative liberties are allocated very much on the basis of private willingness to pay. When it comes to the structure of the mass media, "Although viewers and listeners do not pay cash to broadcasters, each station takes account of the revenue likely to be generated by different programs, and the revenue is in large part a function of the existing audience 'demand' for programming" (Sunstein, 1995: 58).

Self-respect is sustained in part on one's sense of herself as an equal member of the society, capable of sharing the rights and duties associated with political issues and decisions. The possession of the moral sense of being able to form and exercise a conception of justice is fundamental to equality. To show respect for one another is to acknowledge and protect everyone's right to the public use of reason. We have to recognize one another as equals "with respect to making the final authoritative judgments about collective affairs" (Cohen, 2003: 109). The idea of collective self-government underlies the notion of democracy as a self-ruling society. But would self-government be effective without fair opportunities for people to express themselves and being heard in the decisions regarding the course of their society?

In what follows I'm going to discuss why an adequate account of freedom of expression must assure the fair value of communicative liberties.

\section{V.}

First of all, I take for granted that any democratic society must protect freedom of expression. However, I also take as a premise that this should not be understood as merely 
ruling out censorship; indeed, democracy requires as well that individuals have some fair and effective means for bringing their views before public (Scanlon, 2003c: 189).

In a deliberative conception of democracy, the collective character of a decision refers to the fact that it emerges from an institutional arrangement that establishes the appropriate conditions for free public reasoning among equals. According to this view, citizens treat each other as equals by offering reasons for collective decisions that could be considered by all citizens as legitimate.

Deliberative democracy, ..., is not simply about ensuring a public culture of reasoned discussion on political affairs, nor simply about fostering the bare conjunction of such a culture with conventional democratic institutions of voting, parties, elections. The idea instead is manifestly to tie the exercise of power to conditions of public reasoning (Cohen, 1998: 185-6).

In contrast with the views presented in II to IV above, I consider that "equal concern is the sovereign virtue of political community" (Dworkin, 2000: 2). The requirement of shared reasons for the exercise of political power is what represents the full and equal membership of all in the sovereign body responsible for authorizing the exercise of that power (Cohen, 1998: 213-22). It entails, according to the Article 19 of the Universal Declaration of Human Rights, that "everyone has the right to freedom of opinion and expression; this right includes freedom to hold opinions without interference and to seek, receive and impart information and ideas through any media and regardless of frontiers" (UN, 194 - emphasis added).

In order to ensure that citizens are treated as equals in the argumentative process, the basic structure of the society must: (1) promote the free public reasoning by offering, for example, favorable conditions for expression, participation and association; (2) tie the exercise of the coercive power of society to such public discussion, by building an institutional framework that favors the responsiveness and the accountability of political power; and (3) assure that no individual is assigned a lower value by means of its origin, social class, race, sex and other arbitrary condition (Cohen, 1998).

According to Habermas's discourse principle “just those norms deserve to be valid that could meet with the approval of those potentially affected, insofar as the later participate in the rational discourse" (Habermas, 1998: 127 - emphasis added). Hence the citizens must be guaranteed favorable conditions for the exercise of self-expression that are required for self-government, "in a way that provides each person with equal chances to exercise the communicative freedom" (Ibidem). The heart of citizenship, continues Habermas, is composed by both political and human rights, so that public autonomy is not restricted by 
moral rights and, at the same time, individual's private autonomy is not instrumentalized for the purposes of popular sovereignty (Ibidem).

If we consider the requirement that all citizens should be assigned equal opportunities to exercise communicative freedom, we can assume that it is necessary to reduce the asymmetries in the ability to exercise free speech. When such asymmetries are very high, those with more power will presumably express themselves in a way such that their opinions and views are considered indisputable truths. They could suppress qualifications and counter-arguments, and hide clues and conventions that are essential to understand and even challenge their assertions. According to Rawls,

The basis for self-respect in a just society is not ... one's income share but the publicly affirmed distribution of fundamental rights and liberties. And this distribution being equal, everyone has a similar and secure status when they meet to conduct the common affairs of the wider society. No one is inclined to look beyond the constitutional affirmation of equality for further political ways of securing his status (1999: 82).

This is the basis for social self-respect: by affirming the equal basic liberties, citizens of a just society publicly express "their recognition of the worth all citizens attach to their way of life" (Rawls, 1996: 319). Therefore, the communicative practices indispensable to democracy require not only that communicators avoid presenting their own opinions as overpowering, but that they respect the voices from the audience. The commitment must go as far as developing and supporting institutions that contribute to fairness in the opportunities to communicate and that protect the views and social positions threatened of being silenced or marginalized (Ibidem: 172-5).

If we are willing to assure the fair value of communicative liberties, it is important to consider those forms of expression that threaten the ideal of equal opportunities. In order to discourage speeches that are autonomy undermining, we must provide "non-reasonablyrejectable" reasons for applying regulations as the one used in the case mentioned in the beginning of this paper. One form of doing it would be to assume that certain forms of hate speech, for instance, deny some individuals equal opportunities to be equally exercise public and private autonomy. Assuming that the sense people have about their own value and that the confidence they have in their abilities are crucial for their capacity to advance their own ends with self-confidence, we ought to conclude that the basic structure of society must guarantee the social bases of self-respect, securing the status of each as equal citizens (Rawls, 1999: 386; 2003: 59). 
Since this role must be played by the institutions of society's basic structure, regulations may not only restrict but also guarantee the fair value of free speech and, consequently, enable freedom of expression and communication. Press freedom is not in any way innocuous since it can (and it does) harm citizens' ability to exercise collective and individual autonomy. We must have in mind that the structure of the media systems determine the access citizens have to communicative liberties. Rules regarding a fair distribution of the opportunities to establish communication, to influence the political agenda and, more broadly, society's understanding of itself, also contribute to enhance free speech. Preventing media oligopolies and promoting different, public, forms of operating media outlets can be a good way of developing the fair value of communicative liberties ${ }^{43}$.

\section{Tentative conclusion}

In this paper I have suggested that much of the contemporary practice regarding freedom of expression is sustained on the idea that the basic communicative obligation of society is to not impede individuals' self-expression. Some authors see freedom of expression as entitling people to say wherever they want and as justifying non-restrictive ownership of media outlets (Tannsjo, 1985: 547-59). Such a conception of free speech is seen as a corollary of a very broad, almost unconditional, media freedom. In opposition to this line of thought, I defended that much of the promise related to the right to freedom of expression can only be achieved when acts of expression can also be communicated. And that such right must be protected in several ways.

The three views explored justify the protection of certain acts and forms of speech based, respectively, on conceptions of individual autonomy, enlightened understanding and self-determination. I have argued, against them, that they either violate the very principles they use to justify these protections or are an insufficient account for promoting the goals they presumably support.

As an alternative, I have suggested that the justifications for regulating press freedom should rely on values that could be accepted as legitimate by everyone affected by those rules. Based on these premise, I have argued that democracy implies a concern about the equal access to the opportunities of expressing oneself and being heard in the process

43 Unfortunately I will not be able to develop such ideas here. The basic underlying assumption is that the structure of incentives provided by commercial media canont by itself assign people the chance to influence the way media vehicles determine those discourses that have "journalistic" or "public" value. By setting media outlets that operate according to a distinguished logic, we can offer civil society or other organizations the opportunity to influence what counts as a "public" issue or as a "valid" argument. 
of opinion- and will-formation. At the same time, it requires not encouraging the dissemination of views that violate the ideal of equal respect.

The most convincing argument for media freedom appeals to the role these institutions play on individual and public self-determination, as well as to their importance in regulating social and political agency. Given the influence media exercise over society, "providing the informational building blocks to structure views of the world" (Feintuck, 1999: 4-5), and participating in the definition of the chances many citizens will have to receive information from different sources, to exercise freedom of expression, and to communicatively participate in the decisions that will strongly affect their lives, it is reasonable to defend that it should be accountable and, therefore, regulated in order to promote the fair value of communicative liberties. 


\section{References}

Brison, Susan. 1998. "The Autonomy Defense of Free Speech". Ethics Vol. 108, No. 2 (January): pp. 312-339.

Cohen, Joshua. 1993. "Freedom of Expression". Philosopby and Public Affairs, Vol. 22, No. 3 (Summer): pp. 207-63.

Cohen, Joshua. 1998. "Democracy and Liberty". In: Deliberative Democracy. Jon Elster (ed.). Cambridge: Cambridge University Press.

Cohen, Joshua. 2003. "For a Democratic Society". In: Cambridge Companion to John Rawls. Samuel Freeman (ed.). Cambridge: Cambridge University Press.

Dahl, Robert. 2006. On Political Equality. New Haven: Yale University Press.

Dworkin, Ronald. 2000. Sovereign Virtue: The Theory and Practice of Equality. Cambridge, Mass.: Harvard University Press.

Feintuck, Mike. 1999. Media Regulation, Public Interest and the Law. Edinburgh: The Edinburgh University Press.

Fiss, Owen. 1996. The Irony of Free Speech. Cambridge, Mass.: Harvard University Press.

Gastil, J. 2008. Political Communication and Deliberation. Thousand Oaks, CA: Sage Publications, Inc.

Gutmann, Amy; THOMPSON, Dennis. 1996. Democracy and disagreement. Cambridge, Mass.: Belknap Press of Harvard University Press.

Habermas, Jürgen. 1998. Between Facts and Norms: Contributions to a Discourse Theory of Law and Democracy. Cambridge: MIT Press.

Kant, Immanuel. 1991. Kant Political Writings. Cambdridge, Mass.: Cambridge University Press.

Meiklejohn, Alexander. Free Speech and Its Relation to Self-Government. (1948). Available on: http://digital.library.wisc.edu/1711.dl/UW.MeikFreeSp - accessed on Nov. 27 ${ }^{\text {th }}, 2012$.

O’Neill, Onora. "Practices of Toleration". 1990. In: Democracy and the Mass Media. Judith Lichtemberg (ed.). Cambridge: Cambridge University Press.

O’Neill, Onora. 2009. "Ethics for Communication?” European Journal of Philosophy, 17:2, pp. 167-180.

Post, Robert C. 1995. "Meiklejohn's Mistake: Individual Autonomy and the Reform of Public Discourse". In: Constitutional Domains - Democracy, Community, Management. Robert Post. London: Harvard University Press. 
Rawls, John. 1996. Political Liberalism. New York: Columbia University Press.

Rawls, John. 1999. A Theory of Justice (revised edition). Cambridge, Mass.: Harvard University Press.

Rawls, John. 2003. Justice as Fairness: a restatement. Cambridge: Harvard University Press.

Redish, Martin H. and Mollen, Abby M. 2009. Understanding Post's and Meiklejohn's Mistakes: the central role of adversary democracy in the theory of freedom of expression. Northwestern University Law Review Vol. 103, No. 3: pp. 1303-70.

Rummens, S. 2012. Staging Deliberation: The Role of Representative Institutions in the Deliberative Democratic Process. The Journal of Political Philosophy, v. 20, Issue 1, (March): pp. 23-44.

Sandel, Michael. 1998. Democracy's Discontent: America in Search of a Public Philosophy. Cambridge, Mass.: Belknap Press/Harvard University Press.

Scanlon, Thomas. M. 2003a. "Freedom of Expression and Categories of Expression". In: The Difficulty of Tolerance: Essays in Political Philosophy. T.M Scanlon. Cambridge University Press.

Scanlon, Thomas. 2003b. "A Theory of Freedom of Expression". In: The Difficulty of Tolerance: Essays in Political Philosophy. T. M. Scanlon. Cambridge University Press, 2003b.

Scanlon, Thomas. 2003c. "The Difficulty of Tolerance”. In: The Difficulty of Tolerance: Essays in Political Philosophy. T.M Scanlon. Cambridge University Press, 2003c.

Silva, Júlio C. C. B. 2009. Democracia e Liberdade de Expressão: contribuições para uma interpretação política da liberdade de palavra. Tese de Doutorado. DCP-USP, São Paulo, 2009.

Sunstein, Cass. 1995. Democracy and the Problem of Free Speech. New York: The Free Press.

Tannsjo, T. 1985. Against Freedom of Expression. Political Studies, 33(4).

United Nations. The Universal Declaration of Human Rights. Paris, 1948. Available at: http://www.un.org/en/documents/udhr/.

Young, Iris Marion. 2010. Inclusion and Democracy. New York: Oxford University Press. 